\title{
DEPOIS DA CHUVA QUE SE PLANTA: EDUCAÇÃO DO CAMPO, ENSINO MÉDIO TÉCNICO E DE DIREITO
}

\author{
Louise Löbler iD1, Maria Cristina Schefer iD2
}

Resumo: Este texto constitui uma breve revisão de literatura, que surgiu a partir da necessidade de organização de um projeto de pesquisa sobre o Ensino Médio e Técnico na Modalidade Educação do Campo. A seleção dos artigos teve como descritores os seguintes termos: Educação do campo, Ensino Médio, Educação Técnica, Direito Social e o Movimento dos Trabalhadores Rurais Sem Terra - MST. Optamos por publicações dos últimos 10 anos e que tivessem como recorte teórico-conceitual a perspectiva crítico social ou progressista. As publicações convergiram para o entendimento de que: a) não é possível falar em Educação do Campo sem entendê-la como resultado de lutas decanas, que emergiram no MST; b) as garantias constitucionais para a democratização do ensino, requerem novas letras nas Leis que, de fato, garantam especificidades para os jovens do campo; c) o ensino técnico na escola do campo, mais do que necessário, é uma oportunidade ímpar para a melhoria das condições de vida no campo.

Palavras-chave: Educação do Campo; MST; Ensino Médio; Ensino Técnico; Direito Social.

\section{PLANT IT AFTER THE RAIN: RURAL EDUCATION, HIGH SCHOOL, TECHNICAL, AND RIGHTFUL}

Abstract: This text constitutes a brief literature review, which arose from the need to organize a research project on High School and Technical Education in the field of Rural Education. The selection of articles had as descriptors the following terms: Field Education, High School, Technical Education, Social Law and the Landless Workers' Movement - MST. The chosen publications were from the last 10 years, and had as a theoretical-conceptual framework the critical social or progressive perspective. The publications converged to the understanding that: a) it is not possible to talk about Rural Education without understanding it as a result of decades of struggles, which emerged in the MST; b) the constitutional guarantees for the democratization of education, require new letters in the laws, which in fact guarantee specificities for young people in the rural areas; c) technical education in the rural school, more than a necessity, is a unique opportunity for the improvement of living conditions in rural areas.

Keywords: Rural Education; MST; High School; Technical Education; Social Law.

\footnotetext{
${ }^{1}$ Licenciada em História pela Universidade Federal da Fronteira Sul (UFFS/ITERRA). Educadora no Instituto Josué de Castro-Viamão, RS. E-mail: louise-lobler@uergs.edu.br.

${ }^{2}$ Doutora em Educação pela Universidade do Vale do Rio dos Sinos (Unisinos). Profa. Adjunta na Universidade Estadual do Rio Grande do Sul (Uergs), Unidade Litoral Norte. E-mail: mariaschefer@uergs.edu.br.
} 


\section{Introdução}

Quando menina, caminhava na estrada de terra, embaixo da chuva e do sol, para ir à escola, guardava o tênis em uma sacola plástica dentro da mochila e, ao chegar na escola, lavava os pés e calçava o tênis limpo e guardava os chinelos na sacola. E para mim isso nunca foi um sacrifício. Era a esperança que encontrava ao caminhar ao encontro aos livros, aos amigos, a escola. Depois, quando vivenciei perspectivas educacionais libertadoras e emancipadoras no MST, encontrei ali a esperança que procurava na educação, nos acampamentos, nas escolas itinerantes, nas marchas e na produção de alimentos saudáveis (LOUISE LÖBLER, 2021).

A educação é um direito de todos conforme a legislação nacional. Desde a Constituição de 1988, o acesso gratuito ao ensino, em suas especificidades/ modalidades, teve vários avanços. Inicialmente, apenas o Ensino Fundamental era obrigatório; a partir de 2013, a Educação Básica passa a ser obrigatória, o que inclui, compulsoriamente, aqueles que têm entre 4 e 17 anos.

Nesse sentido, vale pensarmos sobre as populações do campo, das pessoas em idade escolar que vivem no campo ou em movimentos pela terra. Visto que, se há leis que obrigam crianças e adolescentes a frequentarem a escola, o acesso ao ensino, a partir da realidade não urbana daqueles que cresceram na lida da terra, também precisa ser pautado, refletido, garantido. Não se pode ignorar que o trabalho no campo se confunde com o crescimento no campo.

Aliás, "graças ao campo, a cidade come", esse dito ecoa entre os camponeses que aspiram à melhoria técnica no campo e precisam de escolas que protejam a harmonia entre os pais e os jovens do campo. Disso depende a segurança alimentar e a melhoria de vida a todos, seja no campo ao na cidade.

Neste texto, há uma revisão de publicações com a temática 'Educação do Campo', entendida enquanto direito social conquistado pelos movimentos dos trabalhadores "sem terra" (MST). Inicialmente, apresentamos a metodologia e, na sequência, os estudos analisados. Mesmo que a organização tenha se dado numa linha cronológica, na reflexão "costuramos" os textos a partir dos assuntos, o que, no nosso entendimento, corroborou o fortalecimento das argumentações dos autores.

\section{Metodologia}

Estudos de revisão de literatura como este, conforme Schefer $(2020)^{3}$, entre outras, servem para que o pesquisador demarque o tema de um novo estudo que projeta desenvolver. Definem-se as características para que a investigação possa ser associada a uma área de concentração de estudos

3 Conferência online na aula de recepção da Linha de Pesquisa III no Programa de PósGraduação em Educação Mestrado Profissional, na Universidade Federal do Rio Grande do Sul RS. 
acadêmicos, conforme a orientação da Coordenação de Aperfeiçoamento de Pessoal de Nível Superior (CAPES).

Desse modo, fazer revisão de literatura, mesmo breve como a que se enseja num texto curto, "é buscar em publicações anteriores um novo estudo, elementos para a constituição da própria identidade de pesquisador, numa tomada de consciência quanto aos arredores de seu objeto de estudo" (IDEM, 2020).

Nesse sentido, é importante que o investigador defina um interstício suficiente para demonstrar avanços, retrocessos e possibilidades em uma determinada temática, a partir de estudos já publicados por pesquisadores de reconhecida credibilidade.

Desse modo, os espaços de consulta e a titulação dos pesquisadores são de suma importância, já que, segundo Schefer (2020), "a credibilidade científica carece de movimentos de acreditação, seja no âmbito das universidades por bancas examinadoras que aprovam e titulam mestres e doutores, seja em revistas com qualis, com avaliação cega, por pares". Ou seja, não basta buscar artigos na internet, nas bibliotecas virtuais, é preciso situar os artigos no tempo e no espaço e verificar por quem foram escritos e a partir de que perspectiva teórica.

Todo o novo estudo carece da revisão de literatura porque "grosso modo, não é preciso descobrir como se faz fogo a cada vez que se quer projetar um novo modelo de lareira" (IDEM, 2020).

A extensão de um estudo de revisão ou de um estudo bibliográfico depende do tipo de trabalho científico que se está a produzir, "o que não libera ninguém, seja o produtor de um ensaio, de um artigo, de um TCC, de uma dissertação ou tese, do rigor metodológico, do ritual de análise das publicações tomadas como ponto de partida" (IDEM, 2020).

Mesmo que a pesquisa bibliográfica ou de revisão de literatura seja o ponto de partida para estudos científicos, ela pode ser também o procedimento de uma pesquisa, ou seja, quando num determinado estudo ou num momento do estudo, o pesquisador toma os achados em investigações anteriores como o seu objeto de análise. Conforme Gil (2007, p. 44), "os exemplos mais característicos desse tipo de pesquisa são sobre investigações sobre ideologias ou aquelas que se propõem à análise das diversas posições acerca de um problema".

Não há neutralidade científica, e a busca de publicações para análises requer que o pesquisador saiba qual a perspectiva teórica que toma como guia, pois ela é fundamental para seleção assertiva do material. Neste estudo, priorizamos publicações que acenem para as pedagogias crítico-sociais ou progressistas. Conforme, Aranha (1996, p. 211),

o esforço da pedagogia progressista se faz na direção de tornar a escola o local de socialização do conhecimento elaborado, possibilitando cada vez mais que as camadas populares tenham acesso à educação e, portanto, ao estágio atual do saber, mesmo reconhecendo os limites do empreendimento. 
Diante do exposto, vale dizer que a opção pela pesquisa social é uma opção pelo compromisso com a vida do outro, com a dignidade humana.

Foram selecionados 12 estudos, tendo a Scientific Electronic Library Online (Scielo Brasil) como principal fonte das publicações, seguida de Anais de Eventos específicos da Educação do Campo. Os descritores para a busca foram os seguintes termos: Educação do Campo, Ensino Médio, MST, Educação Técnica, Educação como Direito Social. Com vistas a traçarmos uma linha cronológica de avanços e desafios sobre a Educação do Campo, optamos por estudos dos últimos 10 anos (2010-2020).

\section{Quadro 1: Seleção de publicações e divisão em tópicos de análise.}

\begin{tabular}{|c|c|c|c|c|c|}
\hline Título & Autor - titulação & $\begin{array}{l}\text { Universidade de } \\
\text { Vinculação }\end{array}$ & Periódico & Ano & Tópico/Assunto \\
\hline $\begin{array}{l}\text { Ensino } \\
\text { médio: em } \\
\text { busca do } \\
\text { princípio } \\
\text { pedagógico }\end{array}$ & $\begin{array}{ll}\text { Paolo Nosella } & - \\
\text { Doutor } & \text { em } \\
\text { Filosofia } & \text { da } \\
\text { Educação } & \end{array}$ & 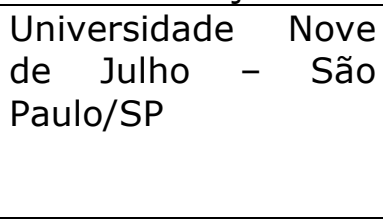 & $\begin{array}{l}\text { Revista } \\
\text { Educação \& } \\
\text { Sociedade }\end{array}$ & 2011 & $\begin{array}{l}\text { Ensino técnico } \\
\text { e o trabalho }\end{array}$ \\
\hline $\begin{array}{l}\text { Os } \\
\text { movimentos } \\
\text { sociais } \\
\text { populares } \\
\text { como } \\
\text { educadores: } \\
\text { contribuições } \\
\text { teóricas e } \\
\text { políticas }\end{array}$ & $\begin{array}{l}\text { Telmo Marcon - } \\
\text { Pós-doutorado } \\
\text { em Educação } \\
\text { Intercultural }\end{array}$ & $\begin{array}{l}\text { Universidade de } \\
\text { Passo Fundo - RS }\end{array}$ & $\begin{array}{l}\text { Revista } \\
\text { Educação - } \\
\text { UFSM }\end{array}$ & 2012 & $\begin{array}{l}\text { Educação do } \\
\text { Campo e o } \\
\text { MST: } \\
\text { Paradigma do } \\
\text { ruralismo } \\
\text { pedagógico }\end{array}$ \\
\hline $\begin{array}{l}\text { Brizoletas: a } \\
\text { ação do } \\
\text { governo de } \\
\text { Leonel Brizola } \\
\text { na Educação } \\
\text { Pública do Rio } \\
\text { Grande do Sul } \\
\text { (1959-1963). }\end{array}$ & $\begin{array}{ll}\text { Claudemir } & \text { de } \\
\text { Quadros- } & \\
\text { Mestre } & \text { em } \\
\text { Educação } & \end{array}$ & $\begin{array}{l}\text { Centro Universitário } \\
\text { Franciscano de Santa } \\
\text { Maria/RS }\end{array}$ & $\begin{array}{l}\text { Revista } \\
\text { Teias } \\
\text { UERJ }\end{array}$ & 2015 & $\begin{array}{l}\text { Educação do } \\
\text { Campo e o } \\
\text { MST: } \\
\text { Paradigma do } \\
\text { ruralismo } \\
\text { pedagógico }\end{array}$ \\
\hline $\begin{array}{l}\text { Juventude, } \\
\text { escola } \\
\text { trabalho: } \\
\text { sentidos da } \\
\text { educação } \\
\text { profissional } \\
\text { integrada ao } \\
\text { ensino médio. }\end{array}$ & $\begin{array}{l}\text { Márcio } \\
\text { Luiz Bernardim - } \\
\text { Doutor em } \\
\text { Educação; Monica } \\
\text { Ribeiro da Silva - } \\
\text { Doutora em } \\
\text { Educação }\end{array}$ & $\begin{array}{l}\text { Universidade } \\
\text { Estadual do Centro } \\
\text { Oeste (UNICENTRO) } \\
\text { Chopinzinho - PR } \\
\text { Universidade Federal } \\
\text { do Paraná (UFPR), } \\
\text { Curitiba - PR }\end{array}$ & $\begin{array}{l}\text { Educação } \\
\text { em Revista } \\
\text { - UFMG }\end{array}$ & 2016 & $\begin{array}{l}\text { Ensino técnico } \\
\text { e o trabalho }\end{array}$ \\
\hline
\end{tabular}




\begin{tabular}{|c|c|c|c|c|c|}
\hline $\begin{array}{l}\text { As } \\
\text { dimensões } \\
\text { da Educação } \\
\text { do Campo }\end{array}$ & $\begin{array}{l}\text { Edna Maria } \\
\text { Querido de } \\
\text { Oliveira Chamon } \\
\text { Pós-doutorado } \\
\text { em Educação }\end{array}$ & $\begin{array}{l}\text { Universidade de } \\
\text { Taubaté (UNITAU), } \\
\text { Taubaté, SP }\end{array}$ & $\begin{array}{l}\text { Revista } \\
\text { Educação - } \\
\text { UFSM }\end{array}$ & 2016 & $\begin{array}{lr}\text { Educação } & \text { do } \\
\text { Campo e o } \\
\text { MST: } \\
\text { Paradigma do } \\
\text { ruralismo } \\
\text { pedagógico }\end{array}$ \\
\hline $\begin{array}{l}\text { Educação e } \\
\text { luta pela terra } \\
\text { no Brasil: A } \\
\text { formação } \\
\text { política no } \\
\text { Movimento } \\
\text { dos } \\
\text { Trabalhadores } \\
\text { Rurais Sem } \\
\text { Terra }\end{array}$ & $\begin{array}{l}\text { Fabiana } r \text { de } \\
\text { Cássia Rodrigues } \\
-\quad \text { Doutora em } \\
\text { Educação }\end{array}$ & $\begin{array}{l}\text { Universidade } \\
\text { Estadual } \\
\text { Campinas } \\
\text { UNICAMP }\end{array}$ & $\begin{array}{l}\text { Revista } \\
\text { Educação \& } \\
\text { Sociedade }\end{array}$ & 2017 & $\begin{array}{lr}\text { Educação } & \text { do } \\
\text { Campo e o } \\
\text { MST: } \\
\text { Paradigma do } \\
\text { ruralismo } \\
\text { pedagógico }\end{array}$ \\
\hline \begin{tabular}{l}
\multicolumn{3}{l}{ Mediação } \\
entre a escola \\
e o novo \\
mundo do \\
trabalho na \\
formação de \\
técnicos de \\
nível médio.
\end{tabular} & $\begin{array}{l}\text { José dos Santos } \\
\text { Souza - Doutor } \\
\text { em Sociologia }\end{array}$ & $\begin{array}{l}\text { Universidade Federal } \\
\text { Rural do Rio de } \\
\text { Janeiro }- \text { Nova } \\
\text { Iguaçu/RJ }\end{array}$ & $\begin{array}{l}\text { Revista } \\
\text { Educação, } \\
\text { trabalho e } \\
\text { saúde - } \\
\text { Fundação } \\
\text { Oswaldo } \\
\text { Cruz/RJ. }\end{array}$ & 2018 & $\begin{array}{l}\text { Ensino técnico } \\
\text { e o trabalho }\end{array}$ \\
\hline $\begin{array}{l}\text { A educação } \\
\text { como direito } \\
\text { social e a } \\
\text { escola como } \\
\text { espaço } \\
\text { protetivo de } \\
\text { direitos: uma } \\
\text { análise à luz } \\
\text { da legislação } \\
\text { educacional } \\
\text { brasileira }\end{array}$ & $\begin{array}{l}\text { Émina Santos - } \\
\text { Doutora em } \\
\text { Desenvolvimento } \\
\text { Sustentável do } \\
\text { Trópico Úmido }\end{array}$ & $\begin{array}{l}\text { Universidade Federal } \\
\text { do Pará, Belém/PA }\end{array}$ & $\begin{array}{l}\text { Revista } \\
\text { Educação e } \\
\text { Pesquisa - } \\
\text { USP }\end{array}$ & 2019 & $\begin{array}{l}\text { Educação } \\
\text { como um } \\
\text { direito social }\end{array}$ \\
\hline $\begin{array}{l}\text { Educação do } \\
\text { Campo e } \\
\text { pedagogia da } \\
\text { alternância: } \\
\text { plano de } \\
\text { estudo como } \\
\text { instrumento } \\
\text { pedagógico no } \\
\text { ensino de } \\
\text { ciências. }\end{array}$ & 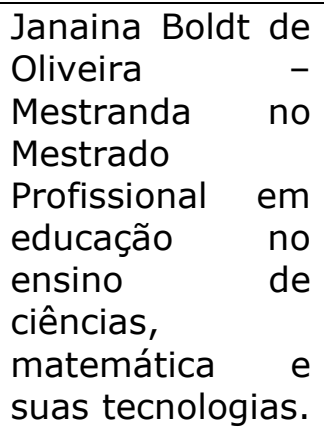 & $\begin{array}{l}\text { Universidade Federal } \\
\text { dos Vales do } \\
\text { Jequitinhonha e } \\
\text { Mucuri - UFVJM - } \\
\text { Teófilo Otoni/MG }\end{array}$ & $\begin{array}{l}\text { XX } \\
\text { Encontro } \\
\text { Nacional de } \\
\text { Didática e } \\
\text { Prática de } \\
\text { Ensino - } \\
\text { ENDIPE, } \\
\text { Rio de } \\
\text { Janeiro }\end{array}$ & 2020 & $\begin{array}{lr}\text { Educação } & \text { do } \\
\text { Campo e } & 0 \\
\text { MST: } & \\
\text { Paradigma } & \text { do } \\
\text { ruralismo } & \\
\text { pedagógico } & \end{array}$ \\
\hline
\end{tabular}




\begin{tabular}{|c|c|c|c|c|c|}
\hline 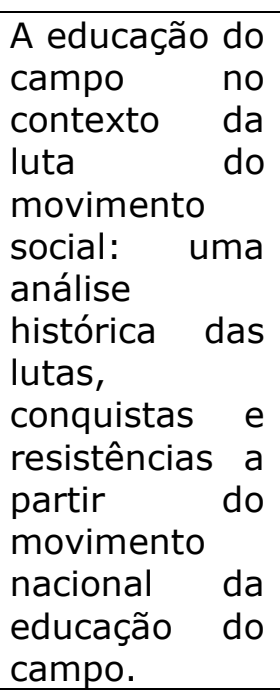 & $\begin{array}{lr}\text { André } & \text { Luiz } \\
\text { Batista da } & \text { Silva - } \\
\text { Doutor } & \text { em } \\
\text { Educação } & \end{array}$ & $\begin{array}{l}\text { Faculdade Nacional } \\
\text { de Educação e } \\
\text { Ensino Superior do } \\
\text { Paraná, Araucária, } \\
\text { PR }\end{array}$ & $\begin{array}{l}\text { Revista } \\
\text { Brasileira } \\
\text { de } \\
\text { Educação - } \\
\text { Maringá/PR }\end{array}$ & 2020 & $\begin{array}{lr}\text { Educação } & \text { do } \\
\text { Campo e o } \\
\text { MST: } \\
\text { Paradigma do } \\
\text { ruralismo } \\
\text { pedagógico }\end{array}$ \\
\hline $\begin{array}{l}\text { Pesquisa } \\
\text { educacional } \\
\text { sobre MST e } \\
\text { Educação do } \\
\text { Campo no } \\
\text { Brasil }\end{array}$ & $\begin{array}{l}\text { Maria Antônia } \\
\text { Souza - Doutora } \\
\text { em Educação }\end{array}$ & $\begin{array}{l}\text { Universidade } \\
\text { Estadual de Ponta } \\
\text { Grossa, Ponta } \\
\text { Grossa/PR } \\
\text { Universidade Tuiuti } \\
\text { do } \\
\text { Paraná, Curitiba/PR }\end{array}$ & $\begin{array}{l}\text { Educação } \\
\text { em Revista } \\
\text { - UFMG }\end{array}$ & 2020 & $\begin{array}{lr}\text { Educação } & \text { do } \\
\text { Campo e o } \\
\text { MST: } \\
\text { Paradigma do } \\
\text { ruralismo } \\
\text { pedagógico }\end{array}$ \\
\hline $\begin{array}{l}\text { Democracia, } \\
\text { educação e } \\
\text { escola: pela } \\
\text { inclusão } \\
\text { educacional. }\end{array}$ & $\begin{array}{lr}\text { Ivar } & \text { César } \\
\text { Oliveira } & \text { de } \\
\text { Vasconcelos } & - \\
\text { Doutor } & \text { em } \\
\text { Educação } & \end{array}$ & $\begin{array}{l}\text { Instituto de Ciências } \\
\text { Sociais } \\
\text { Comunicação } \\
\text { Universidade } \\
\text { Paulista (UNIP) } \\
\text { São Paulo/SP. }\end{array}$ & $\begin{array}{l}\text { Revista } \\
\text { Educação - } \\
\text { UFSM }\end{array}$ & 2020 & $\begin{array}{l}\text { Educação } \\
\text { como um } \\
\text { direito social }\end{array}$ \\
\hline
\end{tabular}

Fonte: Autoras (2021).

Émina Santos, em seu artigo intitulado, A educação como direito social e a escola como espaço protetivo de direitos: uma análise à luz da legislação educacional brasileira, discute a educação enquanto direito social. Para a autora, a história da educação brasileira, o acesso à escola não foi sempre igual para todas as pessoas, o ensino não era obrigatório para algumas idades e, muito menos, gratuito. Tinha por objetivo oferecer a educação para as elites, excluindo, assim, uma considerável parte do povo. Muitos fatores contribuíram para a construção de bases educacionais forjadas no colonialismo europeu, frequentemente reeditadas, como nos anos duros da Ditadura, cabendo rememorar que,

no Brasil, somente a partir do final da década de 1980, especificamente a partir da Constituição Federal, na qual a educação como direito fundamental ganha status constitucional, começou-se a revitalizar o papel da escola na sociedade não somente como espaço de aperfeiçoamento cognitivo, de socialização ou de formação política, mas como espaço protetivo de direitos ... embora os regulamentos mais importantes da política educacional brasileira posteriores à Constituição Federal de 1988 construam uma nova função para a escola - a de ser espaço protetivo de direitos de crianças e adolescentes -, ela ainda funciona como espaço destinado a atividades restritas de escolarização e de reprodução cultural da classe dirigente, cujas práticas e rotinas são 
baseadas na reprodução de valores que regem a lógica do trabalho, do consumo e do ideal de abundância como sinônimo de felicidade, replicando atitudes, valores e comportamentos (grifos nossos, SANTOS, 2019, p. 04).

Diante do exposto, torna-se evidente a contradição instaurada no país, quando, apesar de uma Constituição Cidadã que preconiza a democracia em termos de acesso e permanência na escola, é a lógica de uma 'Sociedade de Consumo' que permeia as relações institucionais.

Quando pensamos em educação como direito, de imediato lembramos que está na Lei a garantia de uma educação pública e gratuita a todas e a todos em território brasileiro. Nesse sentido, a Lei de Diretrizes e Bases da Educação (LDB), Lei no 9.394 de 1996, é destacada por Santos (2019, p. 9) já que

aborda a escola como espaço de formação de cidadania. Embora não destaque expressamente a necessidade de se consolidar a escola como ambiente garantidor e protetor de direitos, percebe-se um avanço democrático a partir das demonstrações de respeito à liberdade e o apreço à tolerância como base para o ensino.

Cabe dizer que a LDB não garante por si só, pelo expresso em suas linhas, a qualidade e o direito ao ensino, porém estar ou não estar previsto em Lei pode resultar em garantias ou estagnações.

Em outro estudo em que o direito à educação é o foco, intitulado Democracia, educação e escola: pela inclusão educacional, de Ivar César Oliveira de Vasconcelos, o autor reitera que "o direito à educação e a uma escola de qualidade já enfrentou e continua enfrentando históricos obstáculos com as consequências inevitáveis à efetiva participação nos rumos do país" (VASCONCELOS, 2020, p. 6). Reitera, ainda, que há muito a se enfrentar para desmistificar posturas que não cabem mais nos tempos atuais.

O pesquisador defende uma educação participativa em que o protagonismo se dê a partir da comunidade escolar, no entendimento de que a "educação, um direito que visa à humanização [...] se constrói por meio da participação de indivíduos por ela compreendidos [...] ela é a totalidade das manifestações e formas de vida que se espalham pela sociedade". (VASCONCELOS, 2020, p. 5 - 6).

Faz-se necessário lembrarmos a história do processo de educação no Brasil para que consigamos construir, coletivamente, novos meios, métodos e formas de uma educação que seja participativa, e força motora para a transformação da sociedade e das pessoas que nela vivem. Numa perspectiva crítica, seriam práticas de ensino, segundo Vasconcelos (2020, p. 9),

pensadas em termos dialéticos, tanto uma como a outra dessas pedagogias - da existência e da essência - serão capazes de fornecer elementos para uma pedagogia favorável ao desenvolvimento humano, a qual precisa considerar que os indivíduos são seres de diálogo e de história. Essa pedagogia, sendo capaz de articular os diversos anseios, valorizará a escola (grifos nossos). 
O autor aponta para o fato de que o ser humano é um ser social, aprende em suas relações com os outros e com o mundo ao seu redor, e que a educação totalizante se dá em espaços situados e tempos datados. Ou seja, há culturalidade no processo educativo. Segundo Vasconcelos (2020, p. 09),

o espaço cultural proporciona o aprendizado significativo favorável ao desenvolvimento da consciência de respeito às singularidades do indivíduo. O mundo como um todo é a casa do ser humano, portanto, oportunidade em todo e qualquer lugar de desenvolvimento da consciência cidadã. Nesse sentido, educar é contribuir para a conscientização dos educandos/educadores, partindose de uma realidade local, com início na leitura do mundo e assim participando deste mundo (grifos nossos).

Há distintas compreensões dos rumos e intencionalidades que a educação deve ter para com os sujeitos. Quando se pensa nos estudantes que moram no campo, nas escolas do campo é preciso pensar em possibilidades de um ensino que seja importante tanto para as gentes do campo quanto para o próprio processo produtivo.

A busca por um ensino técnico que atenda à demanda dos trabalhadores do campo é, pois, tanto uma alternativa quanto um campo de disputa. Esse é o assunto do estudo intitulado Ensino médio: em busca do princípio pedagógico, de Paolo Nosella. Para o autor, "o princípio pedagógico específico do ensino médio, fase final da educação básica, decorre do momento vivido pelo jovem em busca de sua autonomia e identidade moral, intelectual e social". (NOSSELA, 2011, p.1053).

Muitos jovens do campo precisam buscar autonomia financeira, no anseio de contribuírem com a renda familiar. Diante disso, é preciso que se repense qual o modelo de Ensino Médio que pode atender tanto à necessidade de sustento dos estudantes das camadas populares, permitindo que conciliem educação e trabalho, quanto ao aumento de conhecimentos acadêmicos importantes para que esses jovens trabalhadores possam fortalecer seus repertórios de saberes práticos e ampliarem seus potenciais de ação em busca de uma vida digna. Conforme Nossela (2011, p. 1061),

ensino médio, retoma ele o tema da indefinição natural e heurística dos adolescentes que estão em busca de autonomia, identidade pessoal e inserção social. Ajudá-los a descobrir, aos poucos, por meio de repetidos ensaios, sua identidade profunda é tarefa da formação escolar média, oferecendo uma formação omnilateral. Mas, cuidado: formação omnilateral ou integral não significa saber fazer um pouco de tudo ou conhecer os fundamentos científicos de todos os ramos da tecnologia, mas sim saber fazer com excelência algo em sintonia com o próprio talento e, ao mesmo tempo, saber e poder usufruir de todos os bens produzidos pela civilização contemporânea. Está assim lançada uma proposta original da formação omnilateral: aprender a produzir e a desfrutar (grifos nossos).

Os grifos da citação acima mereceram destaque, já que o autor chama atenção para a necessidade de um estudo não generalizado, mas centrado 
nas realidades e condições práticas dos estudantes, com características específicas que levem a aprendizagens que podem se constituir em base para a busca de outros conhecimentos.

É comum a compreensão de que as escolas que ofertam o ensino técnico cumprem a função de formar mão de obra qualificada para o mercado de trabalho atendendo, desse modo, a demandas específicas de linhas de produção, através de qualificação rápida. Contudo, não se pode confundir a preparação rápida para o 'mercado de trabalho', perspectiva de viés liberal e suas regras excludentes, com a preparação para o 'mundo do trabalho', que persegue uma formação integral, democratizante. Diferenciar o ensino para o mercado de trabalho do ensino para o mundo do trabalho é necessário. Segundo Nossela (2011, p. 1053),

não nos enganemos, não é amor à Escola do Trabalho [...] exploração de mão de obra jovem. Aliás, a ideia de oferecer cursos rápidos, práticos, que atendam ao mercado e "acomode" muitos jovens, se apresenta como democrática (grifos do autor).

De outro modo, nem todos são capazes de diferenciar protagonismo de alienação quando se fala em oferta de ensino técnico. Além disso, para muitos, um determinado curso técnico, mesmo que esvaziado de sentido prático, é a única oportunidade que os jovens têm para justificar o estudo para si e para a própria família.

O estudo intitulado Juventude, escola e trabalho: sentidos da educação profissional integrada ao ensino médio, de Luiz Bernardim e Monica Ribeiro da Silva, aponta para o fato de que, optando pelo curso técnico, a juventude revela a crença nela como "potencializadora do emprego [...] com o objetivo de obter um emprego qualificado, que sinalize o rompimento com o passado de condições precárias de trabalho vividas pelos pais, por pessoas próximas ou por eles próprios" (BERNARDIM e SANTOS, 2016, p. 219).

Conforme os autores, o ensino técnico é visto como a solução para os dilemas do estudante trabalhador, é uma oportunidade de estudo, é um tipo de passaporte para outras oportunidades de emprego. Essa impressão de que os problemas estão se resolvendo foram mais bem explicados no excerto abaixo,

elementos chamam a atenção na percepção desse estudante: a compreensão de que o Ensino Médio Integrado contempla disciplinas técnicas que vão além daquelas normalmente ofertadas no Ensino Médio regular; e a percepção de que o enfoque do curso ajuda na qualificação, na identificação de oportunidades de inserção profissional e no encaminhamento para 0 mercado de trabalho. Tais elementos revelam o convencimento do aluno quanto à vantagem da Educação Profissional, que estaria assegurando uma formação similar à do Ensino Médio regular e, ao mesmo tempo, colocandoo em uma condição de diferenciação perante o mercado de trabalho (grifos nossos, BERNARDIM \& SANTOS, 2016, p. 229).

Nem todos os jovens têm o direito a um ensino técnico que vislumbre para além da formação aligeirada e o estudo intitulado Mediação entre a escola 
e o novo mundo do trabalho na formação de técnicos de nível médio, de José dos Santos Souza, pondera sobre a importância de uma escola que priorize o mundo do trabalho. Para o autor, "a mediação entre escola e mundo do trabalho no cotidiano de uma instituição de ensino técnico profissionalizante de nível médio se materializa prioritariamente por meio das atividades de estágio supervisionado" (SOUZA, 2018, p. 130).

Diante disso, o autor coloca a prática de estágio como marco qualificador de uma oferta de ensino técnico, o que pode acenar para a diferenciação entre os tipos de curso ou projetos pedagógicos pelos quais disputam os jovens que buscam (des)alienar os continuadores da cultura do trabalho. Para se ofertar estágio supervisionado, é preciso relações institucionais e estrutura. Conforme Souza (2018, p. 135),

o momento da prática é supervalorizado e assume status de real sentido de todo o conhecimento profissional, o que materializa entre eles o fetiche da prática, em que a formação profissional é entendida como instrumental para ser capaz de produzir e não de pensar sua existência ou conhecer o sentido sócio-histórico da produção.

Os estágios são parte importante da formação, uma vez que os estudantes podem repensar as teorias a partir de novas práticas e podem refletir sobre os gaps de seu processo de ensino-aprendizagem.

O entendimento de que é preciso um Ensino Médio e técnico, enquanto espaço reflexivo, que considere o sentido mais amplo da educação humana foi refletido no estudo intitulado Educação do Campo e pedagogia da alternância: plano de estudo como instrumento pedagógico no ensino de ciências, de Janaina Boldt de Oliveira. Para a autora, é preciso

\begin{abstract}
não somente se formar em um ensino técnico ou profissional, mas também que sua formação seja para a vida e para o trabalho, tornandose um sujeito capaz de ser autônomo e crítico da realidade social. Por fim, o pilar do desenvolvimento do meio, refere-se à capacidade de associar o trabalho da família com o estudo, sendo possível realizar o ensino de ciências com a realidade do estudante, despertando a curiosidade e a vontade de aprender (grifos nossos, OLIVEIRA, 2020, p. 1369).
\end{abstract}

A escola é um meio de ampliar as condições de sustento para a vida, contudo ela precisa contribuir para a manutenção da harmonia familiar com uma proposta que contemple a cultura e as condições reais daqueles que vivem no campo. Ao mesmo tempo, é preciso pensar nos diferentes projetos de vida que podem estar em disputa para a escola do campo. Não podemos esquecer que as grandes indústrias competem diariamente na introdução de novas técnicas produtivas, com a utilização de agrotóxicos e produções em larga escala que afetam diretamente a saúde daquelas e daqueles que vivem e dependem do território rural (ou camponês).

Cabe, aqui, uma breve reflexão sobre a Educação do Campo, com vistas à compreensão de sua essência na perspectiva crítico-social e do Movimento dos Trabalhadores Rurais Sem Terra (MST). No senso comum, a Educação do 
Campo pode ser entendida simplesmente como o ensino que se oferta numa escola do meio rural. Porém, outras práticas educativas e estudos sugerem uma compreensão totalizante do que seria, ou que possa ser, essa educação para os povos do campo.

No estudo intitulado As dimensões da Educação do Campo, Edna Maria Querido de Oliveira Chamon ponderou que é preciso considerar vários aspectos da vida cotidiana camponesa, onde a educação é "a manifestação de um projeto de sociedade, voltada para o equilíbrio entre o bem-estar humano e a preservação da natureza" (CHAMON, 2016, p. 185). Para a autora, situar essa educação totalizante em seus compromissos com terra é o que impede demandas desumanizadas que priorizam o mercado em detrimento da vida no planeta.

Nessa mesma linha, vale pensar que o processo educativo no campo acontece em um tempo pedagógico ímpar, já que não é apartado o ensino escolar da socialização de saberes práticos provindos da lida na terra. Para Chamon, uma Educação do Campo de qualidade envolve especificidades territoriais, "mais do que o direito de ser educado no lugar onde se vive, defende o direito a uma educação pensada a partir desse lugar e com sua participação, vinculada à cultura e às necessidades humanas e sociais da população do campo" (CHAMON, 2016, p. 185). Cabe salientar que estudante do campo, entre as tantas responsabilidades que os bancos escolares exigem, carrega a preocupação com o clima, com a chuva que não chega ou que chega em quantidade acima do esperado para a lavoura. Portanto, o ensino do jovem do campo necessita ser "entendido como conjunção de territórios imateriais (produção de conhecimento, identidade, cultura) e territórios materiais (produção da vida e de seus meios)". (IBIDEM).

Não há como caracterizar o jovem e o Ensino Médio ou o jovem técnico do campo sem situá-los entre as plantações e os costumes de pequenas comunidades. A Educação do Campo é, para Chamon (2016, p. 186),

\footnotetext{
um ato de afirmação política, na medida em que busca uma educação libertadora, voltada para a totalidade do ser humano; e, um ato de afirmação de poder, na medida em que se contrapõe ao processo hegemônico do capital conceito para além da dimensão escolar, reconhecendo e valorizando as diferentes dimensões formativas presentes nos processos de reprodução social nos quais estão envolvidos os sujeitos do campo.
}

Os saberes construídos na escola do campo são coletivos e "brotam" das trocas entre os educadores e educandos, no entendimento de que todos sabem algo, e de que os diferentes saberes podem ser partilhados. De um modo ou de outro, a pesquisadora acenou para a circularidade enquanto método pedagógico na escola do campo, para ação, reflexão, ação, estabelecidos de modo simétrico entre estudante e professor no campo. Nas palavras de Chamon (2016, p. 188), 
instrumental construída pelo capital para a exploração do homem e da natureza, a Educação do Campo aponta para o conhecimento e a transformação da natureza para a liberdade e o bemestar do ser humano (grifos nossos).

A Educação do Campo é uma educação em movimento que precisa ser pensada e organizada a partir desses movimentos onde os estudantes e familiares se encontram. Mesmo quando o professor vai ao campo, é no campo e com o campo que seu projeto de ensino precisa ser construído, desenvolvido, avaliado. A autora reforçou no estudo, que a legislação educacional para a Educação do Campo só foi possível após a Constituição de 1988, com diretrizes de "educação construída pelos povos do campo, para os povos do campo, com o saber dos povos do campo. É uma educação que tem os povos do campo como sujeitos" (CHAMON, 2016, p. 190).

No estudo intitulado $A$ educação do campo no contexto da luta do movimento social: uma análise histórica das lutas, conquistas e resistências a partir do movimento nacional da educação do campo, de André Luiz Batista da Silva, o autor foi enfático em dizer que a Educação do Campo é um "movimento sociopolítico, pois engendrado na luta pela terra, por direitos, por educação" (SILVA, 2020, p. )4). Portando, requer a marcar da coletividade, bem como "a construção de um projeto -pedagógico dos sujeitos do campo e não para os sujeitos do campo" (IBIDEM). O autor chamou a atenção para a historicidade da Educação do Campo como elemento fundante dessa modalidade de ensino, a partir de manifestações, de sofrimentos humanos, de resiliência e de empoderamento da categoria estudantil que vive no campo. Nas palavras de Silva (2020, p. 04),

a educação do campo é resultado da luta dos trabalhadores do campo organizados em movimento social, problematizando a educação rural e o ruralismo pedagógico, buscando uma educação voltada aos interesses dos povos do campo como um projeto de desenvolvimento e vida digna no campo.

A diferença entre o velho e do novo paradigma da Educação do Campo pode ser exemplificado a partir do texto Brizoletas: a ação do governo de Leonel Brizola na Educação Pública do Rio Grande do Sul (1959-1963), de Claudemir de Quadros, em que o pesquisador demonstrou que houve um modelo de educação rural que perdurou até meados da década de 1990 no Brasil. No estado do Rio Grande do Sul, por exemplo, houve a construção das Brizoletas, escolas de arquitetura padrão, entre 1959-1963, que fizeram parte do programa de governo de Leonel Brizola. "As escolinhas do Brizola" visaram, principalmente, a alfabetização, fosse no campo ou na cidade, elas são exemplos apresentados pelo autor daquilo que foi superado, mas que não pode ser esquecido, sob pena de retrocessos. Para Quadros (2015, p. 05),

As escolas, projeção do urbano sobre o rural - missionárias da civilização urbana -, vinham imbuídas de um sentido modernizador e traziam uma missão civilizadora e integradora. As edificações escolares plantadas nas picadas e nos vales deveriam servir, em 
sua simplicidade, como referência para as pessoas e para toda a comunidade (grifos nossos).

É possível dizer que essas escolas do passado, pensadas para os estudantes do campo, sem as gentes do campo, obedeceram não apenas a lógica de ensino das cidades como produziram pressões identitárias com vistas ao abandono de valores e costumes territoriais. Esse paradigma integracionista foi contraposto pelos movimentos sociais do campo e, em termos legais, não tem mais espaço, porém a conquista requer vigília, já que está na contraordem de projetos educacionais que tendem a universalizar e baratear o ensino público.

O sociólogo José dos Santos Souza, em seu estudo intitulado Mediação entre a escola e o novo mundo do trabalho na formação de técnicos de nível médio enfatizou as marcas periféricas das escolas do campo. Para o autor,

\begin{abstract}
as experiências da Educação do Campo têm colocado em questão as ruralidades e diversidades socioculturais que marcam o território brasileiro e o conjunto de povos do campo que foram historicamente secundarizados ou marginalizados na história do País. A partir do reconhecimento da ruralidade territorial em função das experiências socioculturais, da densidade demográfica, das características espaciais e ambientais, coloca-se em evidência a política educacional local, a realidade do fechamento e nucleação de escolas, bem como a política do transporte escolar. Acima de tudo, coloca-se em interrogação o projeto político-econômico que marca e demarca o desenvolvimento do campo no Brasil (SOUZA, 2020, p. 15, grifos nossos).
\end{abstract}

Se há um projeto econômico que não acolhe uma educação singular é sinal que não se pode baixar a guarda do direito conquistado quanto à especificidade da Educação do Campo. Com frequência emergem discursos contraditórios e conservadores calcados na 'modernização de processos de educativos' e resultam no fechamento de escolas, na realocação de estudantes. Em outros termos, na (re)instituição de barreiras espaçotemporais para os moradores do campo. É necessário pensarmos na relação do Movimento dos Trabalhadores Sem Terra e a escola do campo e vice-versa, numa escola que foi inicialmente itinerante, mas lutou para poder se assentar com os seus, sem perder os princípios da luta pela terra. Voltando à Silva (2020, p. $02-03)$,

a educação do campo, como um processo histórico, vincula-se diretamente às lutas dos trabalhadores do campo organizados na forma de movimento social. No caso, organizados a partir do Movimento dos Trabalhadores Sem Terra - MST - que nos processos de luta pela terra e de vida digna nos assentamentos reivindicaram o direito à educação. Lutas pela terra e pela educação nas áreas de assentamento que tiveram seu marco documental no Primeiro Encontro Nacional das Educadoras e Educadores na Reforma Agrária - I ENERA.

No estudo intitulado Os movimentos sociais populares como educadores: contribuições teóricas e políticas, de Telmo Marcon, o pesquisador salientou a 
importância da produção de documentos educacionais a partir das demandas do MST. As lutas nascidas nos acampamentos da década de 1980 passaram a fomentar as políticas para a Educação do Campo, a partir da Constituição Cidadã, dos governos progressistas que foram se estabelecendo no Brasil entre 2004 e 2016. Conforme Marcon (2012, p. 505),

a experiência do acampamento possibilitou inúmeros aprendizados tanto para os sem-terra quanto para as entidades e as organizações que tiveram algum vínculo com ele. Nessas interlocuções, foi possível repensar novas formas de sociabilidade, de solidariedade, de consciência das condições de vida de milhares de famílias no país. A ruptura com o tempo linear do progresso e o discurso sobre a modernização da agricultura viabilizaram identificar novas temporalidades como a do acampamento, da espera, da miséria e da fome, o tempo da reza como tempo da esperança e da força simbólica e religiosa, o tempo do frio e do calor excessivos, o tempo das chuvas e das doenças, o tempo do plantio não feito e da colheita não realizada (grifos nossos).

Diante disso, resta-nos dizer que a escola do campo se fez com uma conjunção de saberes que se diferem das escolas convencionais. São conhecimentos práticos que dizem da vida, muito mais do que sobre a vida.

Por fim, o último estudo por nós analisado foi o de Fabiana de Cássia Rodrigues, intitulado Educação e luta pela terra no Brasil: A formação política no Movimento dos Trabalhadores Rurais Sem Terra. Nele a autora enfatizou que o projeto pedagógico que brotou nas lutas pela terra teve como princípio a coletividade. Os que homens e mulheres que viveram sob a lona se autorreconhecem a partir desse lugar que definiu pertença e não pode ser ignorado, esquecido. Nas palavras da pesquisadora,

\begin{abstract}
ao estarem juntos e conhecerem as histórias de vida uns dos outros, haveria a possibilidade de chegarem à compreensão de que fazem parte da história, uma vez que mudam os lugares e as datas, mas os fatos são muito parecidos - a origem pobre e trabalhadora dos que estão sob a lona preta os fazem enxergar a semelhança de suas trajetórias. Com essas características pedagógicas, o acampa mento se tornou uma das marcas da luta dos sem-terra (grifos nossos, RODRIGUES, 2017, p. 37-38).
\end{abstract}

Resta-nos considerar que, no meio do infortúnio, em pleno à ditadura militar (1964-1984), nasceu o projeto de Educação do Campo no Brasil. Momento em que homens e mulheres dos acampamentos mais sangrentos da história do País, do Estado esperançaram, sonharam com filhos instruídos e comprometidos com os valores do campo.

\title{
3. Discussão e resultados
}

A partir desta revisão de literatura, é possível dizer que: a) não é possível falar em Educação do Campo sem entendê-la como resultado de lutas decanas que emergiram no MST; b) as garantias constitucionais para a 
democratização do ensino requerem novas letras na lei que, de fato, garantam especificidades para os jovens do campo; c) o ensino técnico na escola do campo, mais do que necessário, é uma oportunidade ímpar para a melhoria das condições de vida no campo.

\section{Considerações finais}

Este estudo pretendeu uma aproximação com a temática da Educação do Campo enquanto direito, como resultado da luta do Movimento dos Trabalhadores Rurais Sem Terra. Teve como foco o Ensino Médio e Técnico na perspectiva crítico social ou progressista com vistas a uma educação totalizante.

O projeto de Educação do Campo tem sido (re)construído a partir da realidade das pessoas, dos sonhos que emergem no campo, em diferentes dimensões práticas. Eis que o reencontro com a vida é possível, é verdadeiro, lembrando que o Sem Terra só é por completo quando está na terra. Retomando Rodrigues (2017, p. 42), "a educação por si só não modifica realidade, mas pode alterar a compreensão que os sujeitos sociais possuem a respeito dela, tornando-se, assim, elemento fundamental para o processo de transformação da realidade".

\section{REFERÊNCIAS}

ARANHA, Maria Lúcia de Arruda. Filosofia da Educação. São Paulo, SP: Editora Moderna, (1996).

BERNARDIM, Márcio Luiz. SILVA, Monica Ribeiro. Juventude, escola e trabalho: sentidos da educação profissional integrada ao ensino médio. Educação em Revista, 32 (1), 211 - 234, 2016.

CHAMON, Edna Maria Querido de Oliveira. As dimensões da Educação do Campo. Revista Educação, 41 (1), 183 - 196, 2021.

MARCON, Telmo. Os movimentos sociais populares como educadores: contribuições teóricas e políticas. Revista Educação, 37 (3), 495 - 508, 2021.

NOSSELA, Paolo. Ensino Médio: em busca do Princípio Pedagógico. Educação \& Sociedade, 32 (117), 1050-1066, 2021.

OLIVEIRA, Janaina Boldt de. Educação do Campo e pedagogia da alternância: plano de estudo como instrumento pedagógico no ensino de ciências. In Anais do XX Encontro Nacional de Didática e Prática de Ensino - ENDIPE, ( $p p$. 1365 - 1372). Rio de Janeiro, RJ, 2020. 
QUADROS, Claudemir de. Brizoletas: a ação do governo de Leonel Brizola na Educação Pública do Rio Grande do Sul (1959-1963). Revista Teias, 2 (3), 1 - 12, 2001.

RODRIGUES, Fabiana de Cássia. Educação e luta pela terra no Brasil: A formação política no Movimento dos Trabalhadores Rurais Sem Terra. Revista Educação \& Sociedade, 38 (138), 27- 44, 2021.

SANTOS, Émina. A educação como direito social e a escola como espaço protetivo de direitos: uma análise à luz da legislação educacional brasileira. Revista Educação e Pesquisa, 45 (1), 1 - 15, 2019.

SCHEFER, Maria Cristina. In: Conferência online na aula de recepção da Linha de Pesquisa III. Programa de Pós- Graduação em Educação Mestrado Profissional, na Universidade Federal do Rio Grande do Sul - RS, 2020.

SILVA, André Luiz Batista da. A educação do campo no contexto da luta do movimento social: uma análise histórica das lutas, conquistas e resistências a partir do movimento nacional da educação do campo. Revista Brasileira de História da Educação, 20 (1). 1 - 24, 2020.

SOUZA, José dos Santos. Mediação entre a escola e o novo mundo do trabalho na formação de técnicos de nível médio. Revista Educação, trabalho e saúde, 16 (1). 123 - 140, 2018.

SOUZA, Maria Antônia. Pesquisa educacional sobre MST e Educação do Campo no Brasil. Educação em Revista,36 (1), 1 - 22, 2020.

VASCONCELOS, Ivar César de Oliveira. Democracia, educação e escola: pela inclusão educacional. Revista Educação, 45 (1), 1 - 22, 2019.

Recebido em: 18 de fevereiro de 2021. Aceito em: 16 de agosto de 2021. Publicado em: 15 de dezembro de 2021. 